\title{
FACTORS AFFECTING NON-COMPLIANCE WITH DRUG ABUSE REHABILITATION PROGRAM AT THE CLINIC OF THE NATIONAL NARCOTICS BOARD
}

\author{
Nurhotimah'), Besral²) \\ 1)Master Program of Quality Health Services , Faculty of Public Health, \\ Universitas Indonesia \\ 2)Department of Biostatistics, Faculty of Public Health, Universitas Indonesia
}

\begin{abstract}
Background: Based on the National Drug Abuse Survey, as many as $1.77 \%$ or $3,367,-$ 154 current drug users are aged 10 to 59 years. Sustainable rehabilitation program is one of strategies to reduce the prevalence of drug users. However, there was limited number of studies examining factors affecting non-compliance with sustainable drug abuse rehabilitation program. This study aimed to investigate the factors affecting noncompliance with drug abuse rehabilitation program at the clinic of the national narcotics board.

Subjects and Method: This was a qualitative study conducted at the Compulsory Clinic of National Narcotics Board from July to August 2019. A sample of 10 drug users was selected for this study. The theme of this study was factors affecting non-compliance with the sustainable drug abuse rehabilitation program among drug users at the Compulsory Clinic of National Narcotics Board. The data were obtained by direct indepth interview and observation. The data analyzed by content analysis.

Results: Factors affecting non-compliance with the sustainable drug abuse rehabilitation program among drug users including (1) There was no rehabilitation monitoring system focusing on clients; (2) No community and environmental empowerment supports the recovery clients; (3) Poor rapport between clients and officers; and (4) Lack of family psychoeducation on the drug abuse rehabilitation program.

Conclusion: Factors affecting non-compliance with the sustainable drug abuse rehabilitation program among drug users including (1) No rehabilitation monitoring system focusing on clients; (2) No community and environmental empowerment supports; (3) poor rapport between clients and officers; and (4) lack of family psychoeducation.
\end{abstract}

Keywords: factor, non-compliance, sustainable rehabilitation, drug user, compulsory clinic, national narcotics board.

\section{Correspondence:}

Nurhotimah. Master Program Quality of Health Services in Public Health, Faculty of Public Health, Universitas Indonesia, Depok, West Java. Email: nurhotimah.md1380@gmail.com. Mobile: 08128280197. 